\title{
Surface Tensions of Some Optical Glasses
}

\author{
By Leo Shartsis and Alden W. Smock
}

\begin{abstract}
The surface tension of a number of optical glasses made at the National Bureau of Standards was measured by a modification of the anchor-ring method. At $1,300^{\circ} \mathrm{C}$, the values for the flint glasses were in the range 210 to 230 dynes/cm; those for the bariumcrown glasses were 260 to 310 ; the other types of glasses had intermediate values. Most of the glasses had positive temperature coefficients of surface tension. The surface-tension values increased with increasing periods of time that the glasses were maintained at elevated temperatures immediately prior to measurement. Positive rank correlation coefficients of statistical significance were found between seed quality of optical glasses and such factors as surface tension, pot attack, and amount of gas liberated during the melting process.
\end{abstract}

\section{Introduction}

For all optical elements, freedom from bubbles, known technically as seeds, is desirable, and for some elements, such as reticles, bubble-free glass is absolutely essential to secure satisfactory performance. As bubbles have a glass-gas interface, it seems reasonable to suppose that the surface tension of the glass has a bearing on the stability of the bubble, although it is believed the exact effect of surface tension on the elimination of seeds has not been completely explained.

Bubbles in molten glass may be eliminated either by their rising to the surface and being expelled or by being absorbed as the glass is cooled. The absorption of a bubble in a cooling glass is facilitated by several mechanisms, which at constant volume would lower the gas pressure inside the bubble. Among these may be mentioned (1) the normal lowering in pressure of a gas with decrease in temperature, (2) the lowering in pressure caused by condensation of certain constituents, such as volatilized alkali, lead oxide, etc., (3) absorption of gases, such as $\mathrm{CO}_{2}$ and $\mathrm{SO}_{2}$ by the condensed alkali, and (4) the normal increase in solubility of gases in glass as the temperature is lowered. As the surface tension of the glass acts to decrease the size of the bubble, the volume becomes smaller as the opposing gas pressure becomes less. The pressure on a bubble, due to surface tension, is given by the expression $2 \sigma / r$, where $\sigma$ is the surface tension, and $r$ is the radius of the bubble [1] ${ }^{1}$. Therefore, as the bubble contracts, the pressure due to surface tension increases until it is balanced by the gas pressure, which also increases as the bubble shrinks. This brings into play the increase ir gas solubility normally associated with increasing pressure. The net effect is that bubbles below a certain critical size are reabsorbed as the glass is cooled. This phenomenon has been noted by practical glassmakers when taking samples. The sample while hot may show many small seeds that disappear upon cooling. Thus, as concerns reabsorption of small seeds, high surface tension, when accompanied by an increased gas solubility as the glass is cooled, is a favorable factor.

For the elimination of bubbles by rising to the

\footnotetext{
${ }^{1}$ Figures in brackets indicate the literature references listed at the end of this paper.
} 
surface, low surface tension would seem to be favorable, since, other things being equal and for a given amount of gas in a bubble, the glass with the lower surface tension will have the larger bubble. As, according to Stokes' law, the rate of rise varies as the square of the radius of the bubble, this effect is important. The influence of viscosity on the elimination of bubbles has not been included in this discussion because this property, in contrast to surface tension, changes markedly with temperature and thus may be controlled almost at will.

An experimental approach to the study of the effect of surface tension on the fning rate, i. e., the rate of removal of bubbles by rising to the surface, was attempted by A. A. Appen [2], who used sirups of different surface tensions but of the same viscosity. He found a positive correlation between fining time and surface tension, i. e., the sirups with higher surface tension took longer to fine.

\section{Experimental Method and Calculations}

The pull-on-cylinder method, used by Harrison and Moore [3], was adopted tentatively as the most convenient for measuring the surface tension of glasses. In this method the pull is measured on a hollow vertical cylinder whose lower edge is kept at the level of the undisturbed surface of the test liquid. In working with optical glasses, however, this method was not entirely successful, apparently because some of these glasses do not completely wet the cylinder.

The second method tried involved the maximum pull-on-cylinder principle used by Babcock [4]. In this method the maximum pull is measured on a hollow vertical cylinder, the bottom edge of which is in contact with the molten glass. For accurate results with this method, a correction was applied that involves the density of the glass at the temperature of test. A high accuracy for the density value, however, is not necessary because the correction term usually amounts to only about 3 to 5 percent of the total surface tension value. The following equation developed by Verschaffelt [1] was used in the present investigation:

$$
\sigma=\frac{F}{4 \pi} R\left[1-\left\{2.8284+0.6095 \sqrt{\frac{h}{R}}\right\} \frac{\delta}{\sqrt{h R}}+\right.
$$

$$
\begin{aligned}
& \left\{3+2.585 \sqrt{\frac{h}{R}+0.371} \frac{h \mid \delta^{2}}{R \mid h R}\right], \\
& \sigma=\text { surface tension } \\
& F=\text { maximum extra force } \\
& R=\text { mean radius of cylinder } \\
& h=\frac{F}{\pi R^{2} \rho g} \\
& \rho=\text { density of glass } \\
& 2 \delta=\text { thickness of cylinder wall. }
\end{aligned}
$$

For purposes of computation, the expression $F / 4 \pi R$ is equivalent to $W_{\max }(g / 4 \pi R)$, where $W_{\max }$ is the maximum weight observed, and $g$ is the acceleration of gravity. Then, as $R$ varies with temperature, a table of $g / 4 \pi R$ was set up for different temperatures.

Periodic measurements of the diameter of the platinum cylinder showed that it increased with use. In the early experiments the value for $\mathrm{g} / 4 \pi R$ was 60.66 at $1,300^{\circ} \mathrm{C}$, and this slowly changed to 60.25 in the later experiments.

The densities of some of the glasses at high temperatures had been measured previously by the use of a platinum volumenometer. These data were used to deduce densities for related glasses. In general, it was found sufficiently accurate to compute the correction term for any glass at one temperature only, and then to apply this correction to the measurements at other temperatures.

\section{Apparatus and Procedure}

Figure 1 shows in diagrammatic form the apparatus used. An ordinary analytical balance was used to measure the pull on the cylinder. To counteract the effect of the strong damping action that the viscous glass exerted, the balance was equipped with a sensitive optical lever. The light beam from a galvanometer lamp was directed toward a small front-surface mirror mounted at the center of the balance beam. The reflected beam was focused on a scale at a distance of approximately 30 inches from the mirror. The scale was viewed by means of a small telescope mounted near the balance.

The vertical-tube furnace was wound with 80 percent platinum-20 percent rhodium resistance wire. A small auxiliary heater, separately controlled, was situated at the bottom of the furnace and an Alundum disk, directly above this heater, constituted the floor of the furnace. A noble metal thermocouple projected through a hole in 
the center of the furnace floor and came almost in contact with the platinum dish, 3-in. in diameter, which held the molten glass. Two additional thermocouples were inserted through holes in the split plug that capped the furnace. One of these thermocouples was connected to a potentiometer controller that maintained the temperature of the furnace within $\pm 5 \mathrm{deg} \mathrm{C}$ while surface tension measurements were being made.

In making a determination, several lumps of glass were placed in the dish and lowered gradually into the furnace, which had previously been heated to $700^{\circ}$ or $800^{\circ} \mathrm{C}$. The platinum cylinder

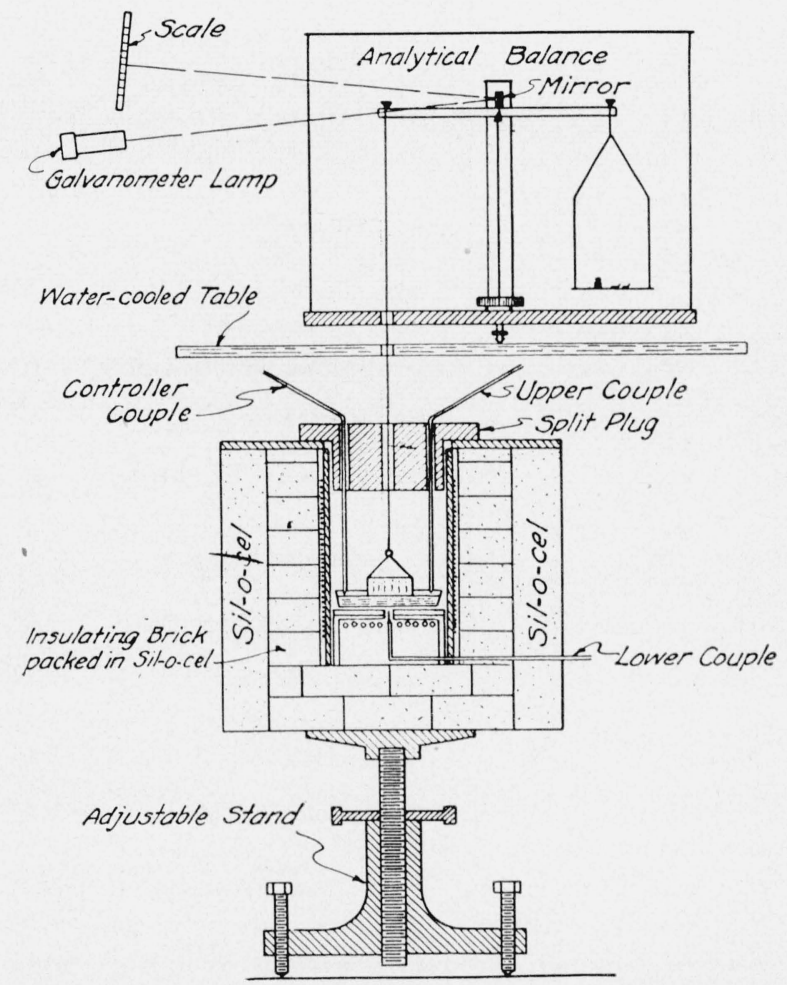

FiguRe 1.-Schematic diagram of surface-tencion apparatus.

then was lowered into a position some distance above the glass and the furnace plugs were inserted. Next, the temperature was increased to $1,300^{\circ} \mathrm{C}$, and the auxiliary heater current was adjusted so that the spread in temperature indicated by the upper and lower thermocouples was within $5 \mathrm{deg} \mathrm{C}$. The cylinder was then weighed, after which the furnace was raised until the bottom edge of the cylinder made contact with the glass. The moment at which contact was made was clearly indicated by the instantaneous damping of the chain vibration.

After contact was established, weights somewhat less than that necessary to balance the downward force exerted by the glass were placed on the weight pan and the balance beam released. By turning the handwheel of the adjustable stand, the furnace was then lowered several millimeters to allow for the stretching of the glass adhering to the cylinder. More weights were slowly added and the furnace position lowered further as the glass continued to stretch, the aim being to have the balance pointer near the scale zero at the time the maximum force was attained. As this point was approached, weights were added in 1-mg steps, sufficient time being allowed for equilibrium to be established. The response of the balance became more pronounced as the end point approached, until, upon the addition of an excess milligram, the balance pointer moved relatively rapidly without coming to equilibrium, indicating that the glass was incapable of supporting the additional weight. This maximum force was remeasured frequently by reestablishing contact and observing the maximum weight the glass could support indefinitely. Measurements were made at 100-deg-C intervals of decreasing temperature until the glass was too viscous to yield in a reasonable time, and the path retraced until $1,300^{\circ} \mathrm{C}$ was again reached.

\section{Data and Discussion}

Table 1 gives the chemical composition, as computed from the batch materials, of the optical glasses studied in this investigation. The data obtained on surface tension are given in table 2 . 
TABLE 1.-Compositions of glasses, computed from batch

[F = flint, $\mathrm{BaC}=$ barium crown, $\mathrm{LC}=$ light crown, $\mathrm{BaF}=$ barium flint, $\mathrm{BSC}=$ borosilicate crown, $\mathrm{CF}=\mathrm{erown}$ flint $]$

\begin{tabular}{|c|c|c|c|c|c|c|c|c|c|c|c|c|}
\hline \multirow{2}{*}{ Glass } & \multirow{2}{*}{$\begin{array}{l}\text { Melt } \\
\text { No. }\end{array}$} & \multicolumn{9}{|c|}{ Component oxides-weight percent } & \multirow{2}{*}{\multicolumn{2}{|c|}{ Other oxides }} \\
\hline & & $\mathrm{SiO}_{2}$ & $\mathrm{PbO}$ & $\mathrm{BaO}$ & $\mathrm{B}_{2} \mathrm{O}_{3}$ & $\mathrm{Na}_{2} \mathrm{O}$ & $\mathrm{K}_{2} \mathrm{O}$ & $\mathrm{ZnO}$ & $\mathrm{As}_{2} \mathrm{O}_{3}$ & $\mathrm{Sb}_{2} \mathrm{O}_{3}$ & & \\
\hline F $5725 / 42.2$ & 5820 & 55.1 & 31. 7 & 1.0 & & 5.0 . & 6.9 & & 0.3 & 0.5 & & \\
\hline F $5795 / 40.9$ & 6993 & 53.1 & 35.5 & 0.6 & 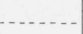 & 0.4 & 9.6 & & .3 & . & & \\
\hline F $605 / 37.9 \ldots$ & 4194 & 47.6 & 40.9 & & - . - & 2.2 & 8.8 & & .5 & $\cdots$ & & \\
\hline F $617 / 36.6$ & 6984 & 45.6 & 43.1 & & & 4.7 & 6.1 & & .5 & & & \\
\hline F $620 / 36.2 \ldots$ & 6841 & 45.6 & 45. 2 & & & 3.0 & 5.7 & & .5 & & & \\
\hline F $649 / 33.8 \ldots$ & 6934 & 41.2 & 51.1 & $\ldots$ & . & 0.7 & 6.5 & & .5 & -. & & \\
\hline F $666 / 32.4 \ldots$ & 6937 & 39.3 & 54.4 & & & $\ldots$ & 6.0 & & .3 & & & \\
\hline F $6725 / 32.2 \ldots$ & 4316 & 38.8 & 55.4 & & & $\ldots$ & 5.5 & & .3 & . & & \\
\hline F $720 / 29.3 \ldots$ & 6860 & 34.1 & 62.4 & & & $\ldots$ & 3.2 & & .3 & $\ldots$ & & \\
\hline F $750 / 27.7 \ldots \ldots$ & 6397 & 31.2 & 66.2 & $\ldots$ & . & 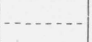 & 2.3 & 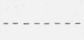 & .3 & $\cdots$ & & \\
\hline $\mathrm{BaC} 541 / 59.8 \ldots$ & 6990 & 58.8 & ..... & 19.9 & 3.4 & 3.2 & 10.3 & 4.1 & .3 & & & \\
\hline $\mathrm{BaC} 5725 / 57.4 \ldots$ & 6822 & 45. 2 & ..... & 28.7 & 6. 2 & 1.4 & 7.0 & 7.5 & .3 & .7 & $\mathrm{Al}_{2} \mathrm{O}_{3} 3.0$ & \\
\hline $\mathrm{BaC} 611 / 58.8 \ldots \ldots$ & 6680 & 38.3 & 0.2 & 42.8 & 10.7 & $\ldots$ & $\ldots$ & $\ldots$. & .4 & .2 & $\mathrm{Al}_{2} \mathrm{O}_{3} 2.9 ; \mathrm{CaO} 4.5$ & \\
\hline $\mathrm{BaC} 617 / 55.0 \ldots$ & 6903 & 37.3 & 1.4 & 44.8 & 4.4 & 0.2 & 0.4 & 5. 6 & .3 & .7 & $\mathrm{Al}_{2} \mathrm{O}_{3} 4.9$ & \\
\hline $\mathrm{BaC} 620 / 60.0 \ldots \ldots$ & 6495 & 37.2 & …. & 41.6 & 11.0 & $\ldots$ & … & . & .3 & .2 & $\mathrm{BeO} 4.2 ; \mathrm{CaO} 3.5 ; \mathrm{ZrO} 2.0$ & \\
\hline $\mathrm{BaF} 584 / 46.0 \ldots$ & 6494 & 49.8 & 18.8 & 13.4 & $\ldots$ & 1.6 & 8.2 & 7.8 & .5 & & & \\
\hline BaF 588/53.4 $\ldots$. & 4848 & 45.8 & 10.0 & 25.9 & 8.8 & 0.8 & 6.7 & $\ldots$. & .5 & ... & $\mathrm{ZrO}_{2} 1.5$ & \\
\hline $\mathrm{BaF} 604 / 43.5 \ldots \ldots$ & 4411 & 45.7 & 23.3 & 13.6 & & 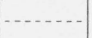 & 8.9 & 8.1 & .4 & & & \\
\hline BSC $511 / 63.5 \ldots$ & 6292 & 68.8 & & & 8.5 & 7.8 & 14. 7 & $\ldots$ & .2 & & & \\
\hline BSC $517 / 64.5 \ldots \ldots$ & 6929 & 66.4 & & & 12.4 & 8.2 & 12.0 & 0.5 & .5 & & & \\
\hline BSC $536 / 64.5 \ldots \ldots$ & 6471 & 63.4 & & & 13.0 & -.... & 6.2 & $\ldots$. & .4 & & $\mathrm{BeO} 2.0 ; \mathrm{SrO} 10.0 ; \mathrm{Li}_{2} \mathrm{O} 5.0$ & \\
\hline LC $5125 / 60.5 \ldots$ & 6931 & 71.9 & & & 5.0 & 14. 7 & 5. 0 & & $\cdots$ & 1. 2 & $\mathrm{CaO} 2.2$ & \\
\hline LC $5145 / 59.5 \ldots \ldots$ & 5767 & 71.2 & & & 5.0 & 14. 7 & 5. 0 & & $\ldots$ & 1. 2 & $\mathrm{CaO} 2.9$ & \\
\hline LC $523 / 58.6 \ldots \ldots \ldots$ & 6910 & 70.2 & -... & $\cdots$ & 1.5 & 14.0 & 2.5 & & $\cdots$ & 1.2 & $\mathrm{CaO} 9.4 ; \mathrm{Cl} 0.7 ; \mathrm{SO}_{3} 0.5$ & \\
\hline CF $5295 / 51.6 \ldots$ & 1280 & 65.1 & 10.0 & 0.2 & & 11.6 & 6.1 & 5.0 & .2 & 1.8 & & \\
\hline NBS Standard Samp & n....... & 74.1 & - n & $\ldots$ & & 16.85 & 0.04 & & .10 & & $\mathrm{CaO} 4.65 ; \mathrm{MgO} 3.23$ & ' \\
\hline NBS Standard Samp & (n....... & 65. 35 & 17.5 & 1.40 & & 5. 70 & 8.4 & & & & & \\
\hline
\end{tabular}

a Standard Sample values are from chemical analyses. 
TABLE 2.-Surface tension of some optical glasses

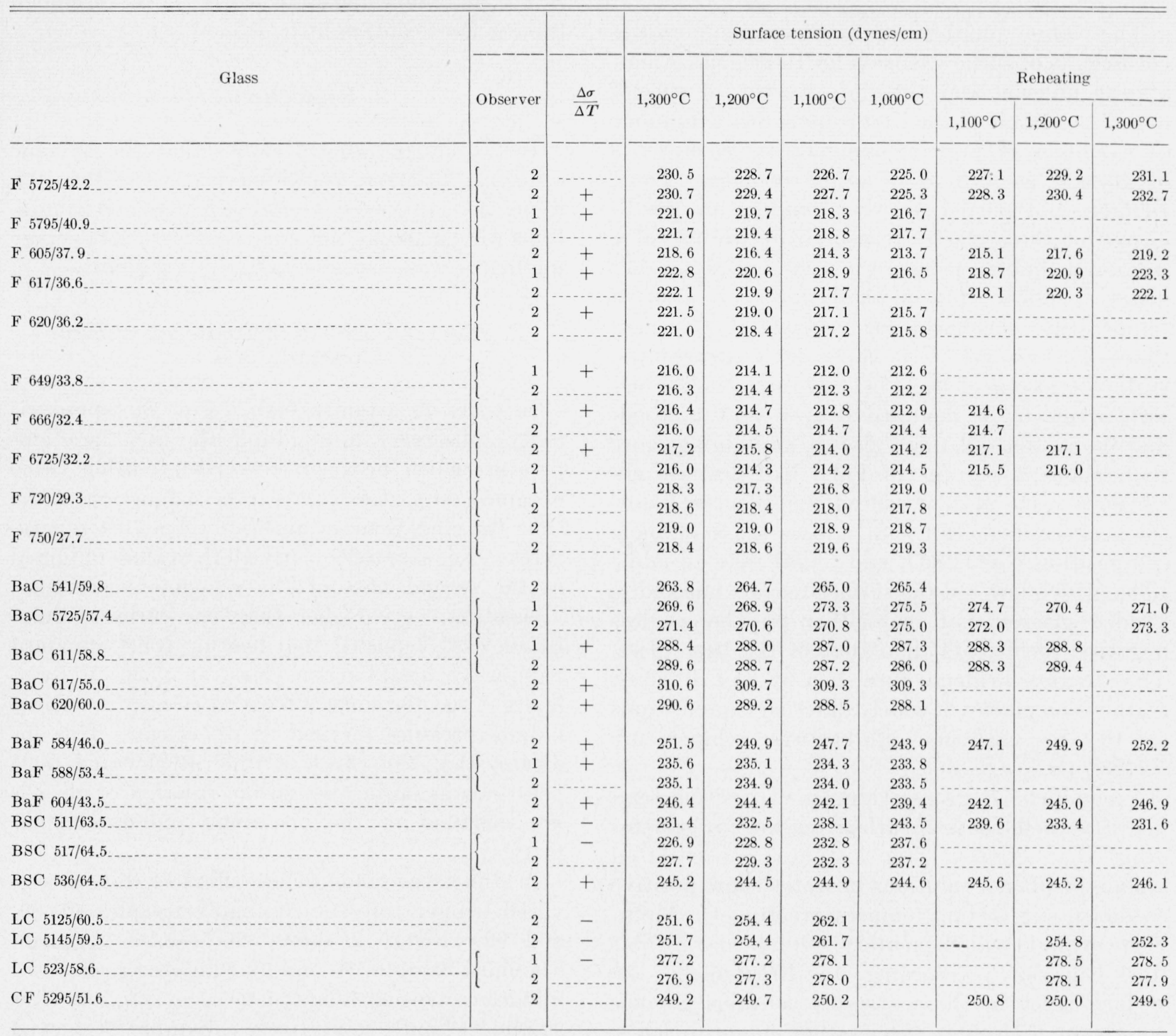




\section{Positive Temperature Coefficients}

The large number of positive temperature coefficients of surface tension for these glasses may appear unusual and therefore worthy of special note. A search of the literature shows a number of examples of positive temperature coefficients of glasses, as well as of other systems. Thus, Badger [5] reported positive temperature coefficients for three glasses measured by the use of a maximum bubble pressure method. Bradley [6], using a sessile drop method, found a positive temperature coefficient for vitreous $\mathrm{B}_{2} \mathrm{O}_{3}$ in the range $300^{\circ}$ to $500^{\circ} \mathrm{C}$. Appen [2] measured the surface tensions of the $\mathrm{PbO}-\mathrm{SiO}_{2}$ and $\mathrm{Na}_{2} \mathrm{O}-\mathrm{PbO}$ $\mathrm{SiO}_{2}$ series by a modified drop-weight method, and found that all these glasses, containing more than about 3 percent of $\mathrm{PbO}$, had positive coefficients. He also measured the effect of additions of various oxides to a base glass of mole composition $\mathrm{Na}_{2} \mathrm{O} .2 \mathrm{SiO}_{2}$ and found that all additions, which lowered the surface tension markedly, yielded glasses that had either positive or less negative coefficients than that of the base glass. Thus there is evidence furnished by four different methods on glasses of widely differing compositions as to the existence of positive temperature coefficients.

Freundlich [7] gives examples of positive temperature coefficients of surface tension for systems other than glasses. For instance, concentrated aniline or phenol solutions in water show positive coefficients in certain temperature ranges. Methylene cyanide and elementary sulphur also exhibit this behavior. According to Freundlich, the surface layer in these systems contains a component or molecular species that tends to lower the surface tension. As the temperature is raised this molecular species becomes more soluble in the main body of the liquid and is withdrawn from the surface, thereby raising the surface tension.

Tables 1 and 2 reveal that in general the optical glasses that are low in either silica or alkalies or both have positive temperature coefficients. The flint glasses, which have relatively high percentages of $\mathrm{PbO}$, necessarily have low percentages of silica, alkalies, or both, but the mere presence of $\mathrm{PbO}$ to the extent of even 10 percent is not sufficient to cause a positive coefficient, as evidenced by the example of CF 5295. On the other hand, $B a C 611,617$, and 620 , as well as $B S C$ 540, show positive coefficients, although these glasses contain little or no $\mathrm{PbO}$.

\section{Reproducibility}

Inspection of table 2 shows that the average difference between two observers is less than 0.8 dyne $/ \mathrm{cm}$. In cases where duplicate determinations were made by the same observer, the average difference was also less than $0.8 \mathrm{dyne} / \mathrm{cm}$.

\section{Effect of Duration of Treatment at High Temperatures}

In order to attain a high degree of reproducibility, observers must duplicate the time-temperature curve because the surface tension value obtained on a glass seems to be a function of the time the glass is maintained at elevated temperatures. For example, nearly all the values obtained in the second part of the schedule, designated "reheating," are higher than the earlier values. Bradley [6], reported that heating NBS Standard Sample 89 (lead-barium glass) at $1,500^{\circ} \mathrm{C}$ for 5 hours raised the surface tension, as measured by a bubble pressure method, 2 dynes $/ \mathrm{cm}$. This indicates that the effect of time at elevated temperatures in raising the surface tension of glass is not confined to the maximum pull-on-cylinder method.

A study was made of the effect of time at elevated temperatures on Standard Samples 80, 89, and 92. Figure 2 shows the results obtained. Standard Samples 80 and 92 exhibited a slow rise in surface tension followed by a leveling off after 22 and 44 hours, respectively. Sample 89 showed a continuous increase in surface tension up to 94 hours, when the test was discontinued.

\section{Comparison With Other Observers}

Both Badger [5], and Bradley [6], have reported surface tension measurements made by the use of a maximum-bubble pressure method, and these are compared in table 3 with the values obtained here. In general, the values obtained in this investigation are lower. However, considering differences in time-temperature schedule and the different methods used, the agreement may be considered satisfactory. 


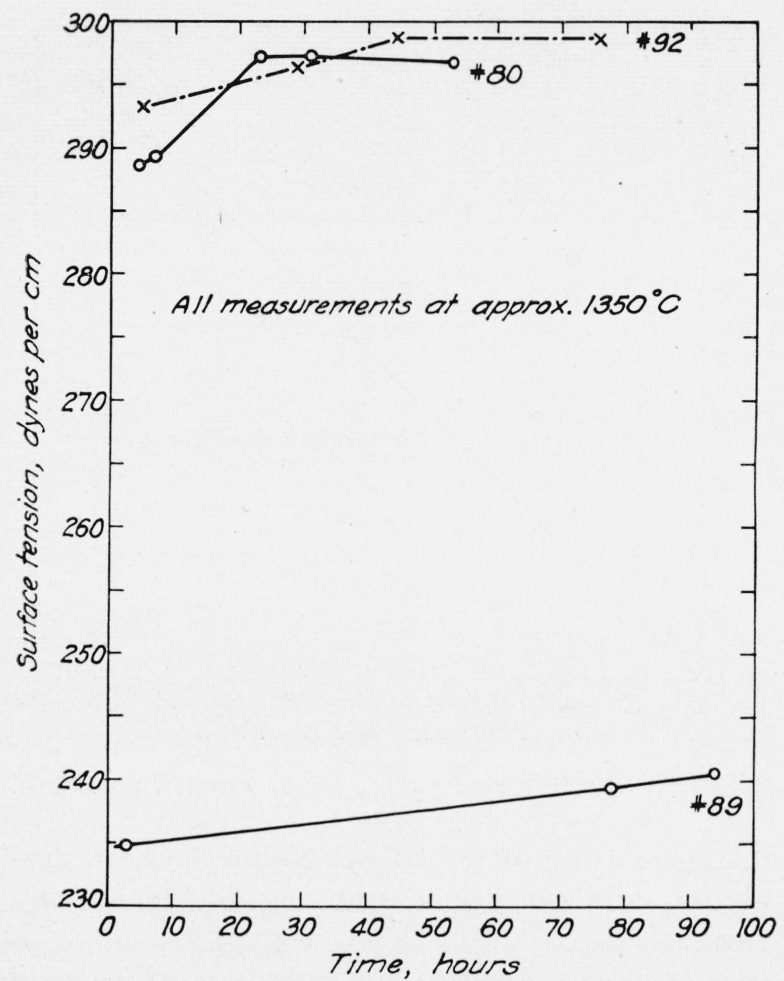

FIGURE 2.-Increase of surface tension with duration of treatment at elevated temperature for Standard Samples 80,89 , and 92.

TABLE 3.-Comparison of surface tension values

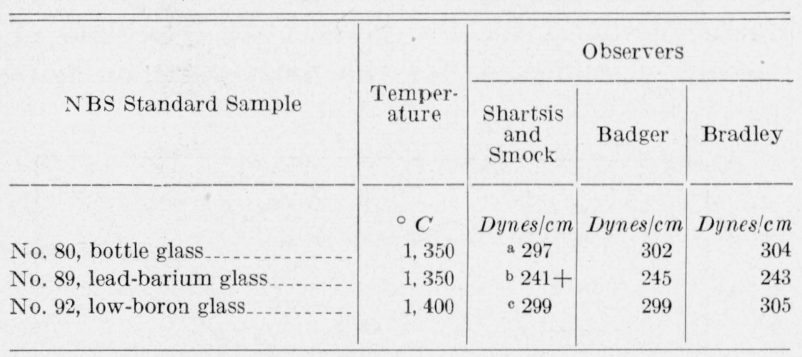

s Heated 23 hours at $1,350^{\circ} \mathrm{C}$.

b Value still rising after 94 hours at $1,350^{\circ} \mathrm{C}$.

c Heated 40 hours at $1,400^{\circ} \mathrm{C}$.

The surface tension of $\mathrm{B}_{2} \mathrm{O}_{3}$ in the range $700^{\circ}$ to $1,400^{\circ} \mathrm{C}$ was measured and a plot of these data is shown in figure 3 . A straight line was fitted to the data by means of least squares, and values of 58.2 at $300^{\circ} \mathrm{C}$, and 65.3 at $500^{\circ} \mathrm{C}$, were deduced from the extrapolation of this line. The corresponding values reported by Bradley [6], using a sessile drop method, were 57 and 67 dynes $/ \mathrm{cm}$. This agreement is well within the reproducibility of the sessile drop method.

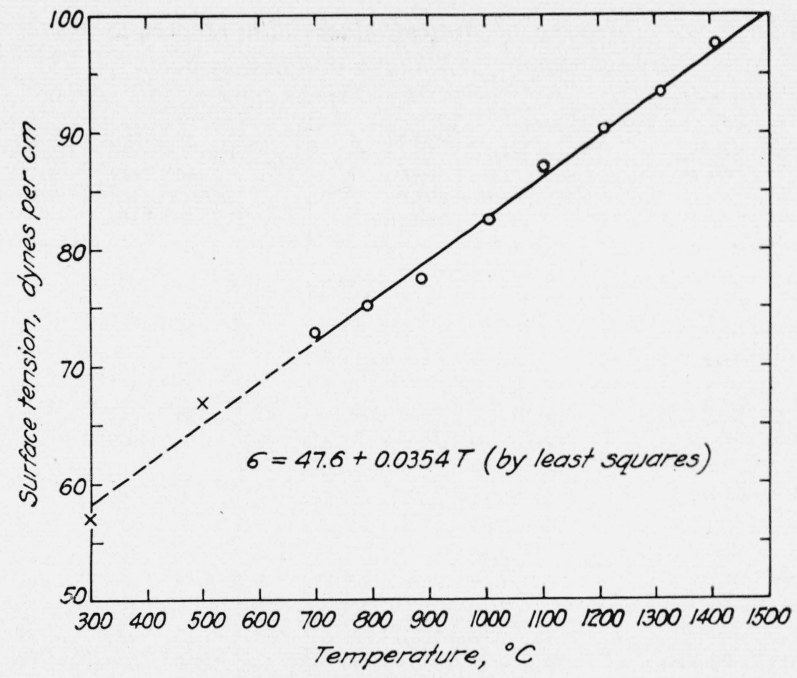

Figure 3.- Surface tension versus temperature of $\mathrm{B}_{2} \mathrm{O}_{3}$.

Points in circles by maximum pull-on cylinder method, crosses by Bradley, who used a sessile drop method.

\section{Relation Between Seed Quality, Surface Tension, and Other Factors}

To investigate the possible relation between surface tension and seed quality, which was one of the aims of this study, an analysis was made of the records of some 2,500 melts produced at the optical glass plant of the National Bureau of Standards. The system in use was for inspectors to rate the quality of the optical glass with respect to several properties, seed quality being one of the properties considered. Excellent melts were rated $A$, good ones $B$, fair ones $C$, poor ones $D$, and very poor ones $E$. The letters were converted to numbers by assigning the number 1 to $A$ pots, 2 to $B$ pots, etc. These numbers were then averaged for all the melts of a given glass and are to be found in the second column of table 4. Ratings for the corrosiveness of the various glasses toward the pots used in their manufacture were deduced from the data of Parsons [8]. The volume of gas liberated in the melting process was calculated from the batch components in cubic feet per pot of glass at $0^{\circ} \mathrm{C}$ and $760-\mathrm{mm}$ pressure. The volatilization of batch materials, other than $\mathrm{CO}_{2}$, $\mathrm{NO}_{2}, \mathrm{O}_{2}$, and $\mathrm{H}_{2} \mathrm{O}$ vapor, was not considered. 
TABLE 4.-Ranking of optical glass with respect to seeds, surface tension, pot attack and gas-in batch

\begin{tabular}{|c|c|c|c|c|c|c|c|c|}
\hline Glass & $\begin{array}{l}\text { Num- } \\
\text { ber of } \\
\text { pots }\end{array}$ & $\begin{array}{l}\text { Seed } \\
\text { rat- } \\
\text { ing }\end{array}$ & $\begin{array}{l}\text { Rank } \\
\text { in } \\
\text { seed } \\
\text { qual- } \\
\text { ity }\end{array}$ & $\sigma$ & $\begin{array}{l}\text { Rank } \\
\text { in } \sigma\end{array}$ & $\begin{array}{l}\text { Rank a } \\
\text { in pot } \\
\text { attack }\end{array}$ & $\begin{array}{l}\text { Gas } \\
\text { com- } \\
\text { puted } \\
\text { per } \\
\text { pot }\end{array}$ & $\begin{array}{c}\text { Rank } \\
\text { in } \\
\text { gas }\end{array}$ \\
\hline & & & & $\frac{1,300^{\circ}}{C}$ & & & $f t^{3}$ & \\
\hline F $605 / 37.9$ & 7 & 1.71 & 1 & 218.6 & 5 & 3 & 1549 & 8 \\
\hline F $666 / 32.4 \ldots \ldots$ & 4 & 2.00 & 2 & 216.2 & 1 & 4 & 998 & 2 \\
\hline F $649 / 33.8 \ldots$ & 60 & 2.02 & 3 & 216.2 & 2 & 7 & 1111 & 4 \\
\hline $\mathrm{BaF} 604 / 43.5 \ldots$ & 65 & 2. 31 & 4 & 246.4 & 12 & 13 & 1763 & 10 \\
\hline BSC $511 / 63.5 \ldots \ldots$ & 110 & 2.34 & 5 & 231.4 & 10 & 8 & 3695 & 14 \\
\hline F $5795 / 40.9 \ldots \ldots$ & 166 & 2.59 & 6 & 221.3 & 7 & 2 & 1256 & 7 \\
\hline F $620 / 36.2 \ldots \ldots$ & 252 & 2.59 & 7 & 221.2 & 6 & 6 & 999 & 3 \\
\hline F 617/36.6 & 166 & 2. 69 & 8 & 222.5 & 8 & 5 & 1135 & 5 \\
\hline $\mathrm{BaF} 584 / 46.0$ & 9 & 2.89 & 9 & 251.5 & 13 & 12 & 1731 & 9 \\
\hline BSC $517 / 64.5 \ldots$ & 1,530 & 2. 94 & 10 & 227.3 & 9 & 9 & 4005 & 15 \\
\hline F $6725 / 32.2 \ldots \ldots$ & 2 & 3.00 & 11 & 216.6 & 3 & 10 & 1154 & 6 \\
\hline $\mathrm{BaC} 541 / 59.8 \ldots \ldots$ & 28 & 3.28 & 12 & 263.8 & 14 & 15 & 2480 & 12 \\
\hline $\mathrm{BaC} 5725 / 57.4 \ldots \ldots$ & 893 & 3.39 & 13 & 270.5 & 15 & 16 & 4500 & 16 \\
\hline F $720 / 29.3 \ldots \ldots$ & 24 & 3.46 & 14 & 218.5 & 4 & 11 & 650 & 1 \\
\hline LC $523 / 58.6 \ldots$ & 8 & 3.50 & 15 & 277.1 & 16 & 1 & 2000 & 11 \\
\hline $\mathrm{BaC} 617 / 55.0 \ldots \ldots$ & 18 & 3.72 & 16 & 310.6 & 18 & 18 & 7733 & 17 \\
\hline BaF 588/53.4 $\ldots . .$. & 4 & 4.00 & 17 & 235.3 & 11 & 14 & 3560 & 13 \\
\hline $\mathrm{BaC} 611 / 58.8 \ldots \ldots$ & 16 & 4.56 & 18 & 289.0 & 17 & 17 & 7771 & 18 \\
\hline
\end{tabular}

a Ranks estimated by W. H. Parsons, based on his experience with petrographic examinations of pots.

Rank correlation coefficients of $+0.62,+0.61$, and +0.51 , were obtained by computation for seed quality versus surface tension, pot attack and gas-in-batch, respectively. These values are large enough to be statistically indicative [9]. Figures 4,5 , and 6 , show the departure of the individual points from the 45-degree line, which represents perfect rank correlation. A remarkably high

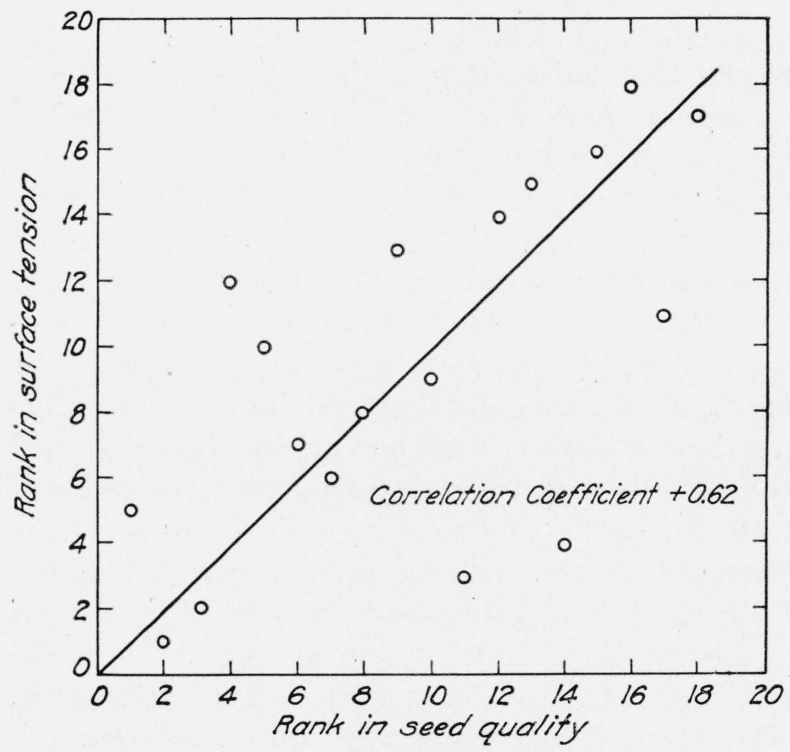

FIGURE 4.-Rank in seed quality versus rank in surface tension.

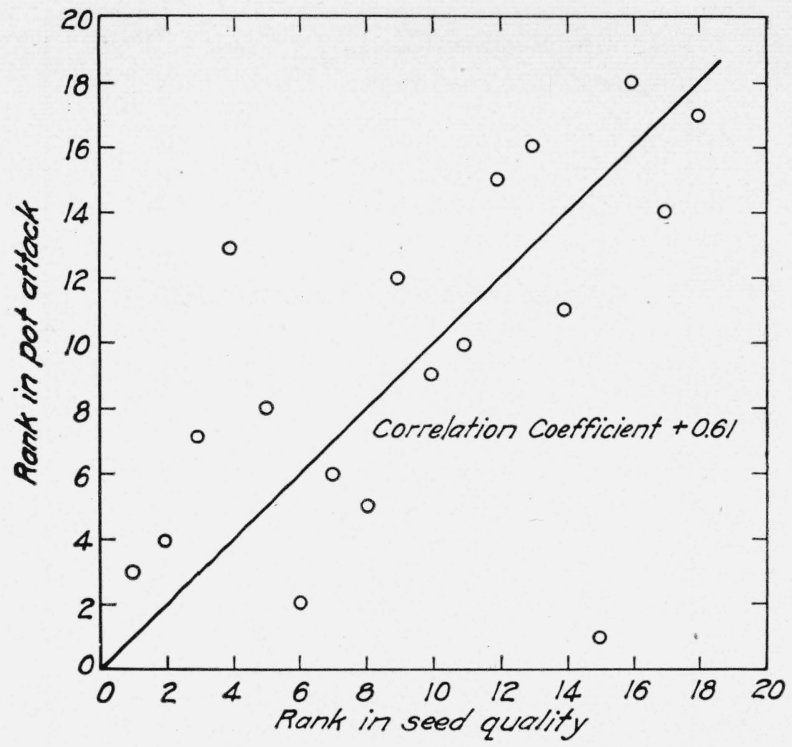

Figure 5.-Rank in seed quality versus rank in pot attack.

rank correlation of +0.82 was found between gasin-batch and surface tension, as illustrated by figure 7 .

Attention is called to the weakness of some of the data upon which these correlations are based, and caution is advised in their full acceptance. The inspectors' ratings were affected by the factors that influence subjective ratings, personal temperament, demand for the glass, etc. The data of Parsons were based, for the most part, on pots that failed in service by leaking.

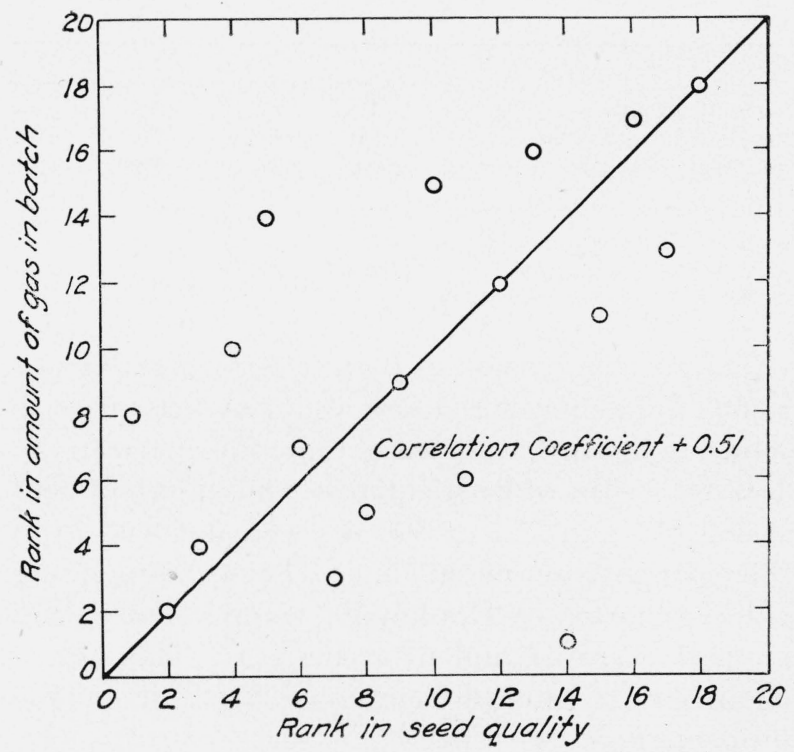

FiguRE 6.-Rank in seed quality versus rank in amount of gas in batch. 
To substantiate these correlations, more and better data are necessary. Quantitative values for pot attack might be obtained by using tracers incorporated in the pot body. The effect of different amounts and kinds of gas might be investigated by varying the batch components used in making a glass of a certain composition. A quantitative system of seed ratings with cross checking by different inspectors should improve the objectivity of these estimates.

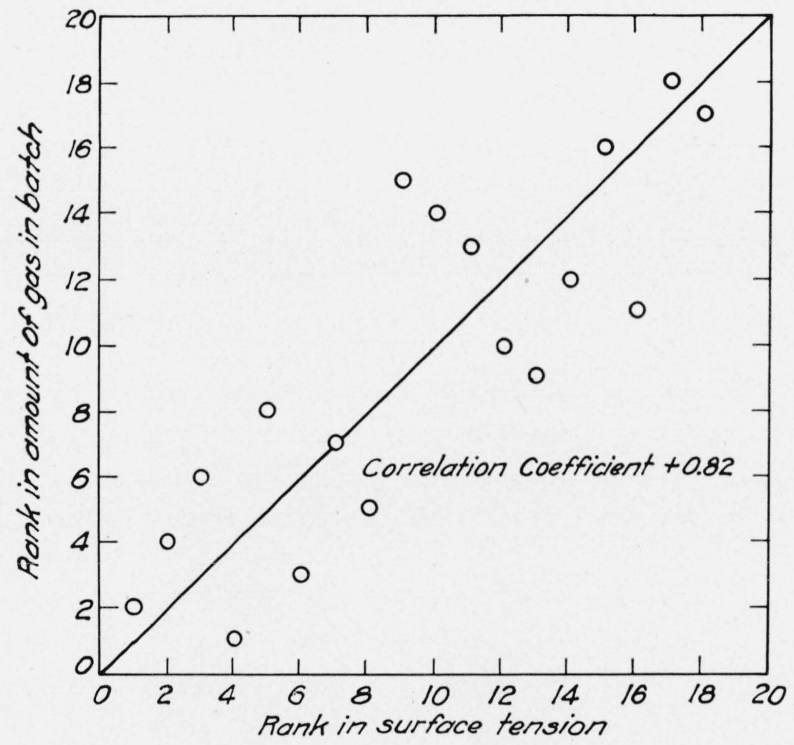

FIGURE 7.-Rank in surface tension versus rank in gas in batch.

Many of the favorable factors that have a bearing on seed quality occur together, and so do many of the unfavorable ones, thus making difficult the estimation of the exact contribution of each to the final result. Thus, in general, the barium crowns show high pot corrosion, have high surface tensions, and liberate large amounts of gas during the melting process. On the other hand, the flint glasses usually have low surface tensions, low corrosiveness, and liberate small amounts of gas when melting down. The simultaneous occurrence of like factors stems from the chemical com- position. When exceptions to the rule that like factors occur together arise, the effect of the exceptional property can be noted. Thus, by reference to table 4, one can see that F 720 is poor for seeds, which may probably be explained by its ability to corrode the pot to a far greater extent than the other flints.

In addition to the factors already mentioned, it is known that a poor melting schedule or faulty furnace conditions may also cause seeds in glasses. It is possible that the good quality of $B a \mathrm{~F} 604$, which seems unexpected because of its high corrosiveness and only moderate surface tension and gas content, is to be ascribed to an exceptionally good melting schedule. This theory could be tested by melting the other barium flints on a similar schedule with whatever changes are necessary because of differences in viscosity or fining time. The chief advantages of the data and correlations advanced here are in the indications as to the possible lines of attack in disentangling the factors operative in determining the seed quality of the optical glasses.

\section{Summary}

The surface tensions of a number of the optical glasses made at the National Bureau of Standards have been measured by a modification of the anchor-ring method. The values found seemed to be affected by the length of time the glasses were maintained at elevated temperatures immediately prior to measurement. Most of the glasses, especially those containing considerable amounts of $\mathrm{PbO}$, were found to have positive temperature coefficients of surface tension. Positive rank correlations of statistical significance were found between seed quality and such factors as surface tension, pot attack, and amount of gas liberated during the melting process. In general, the flints rank low in surface tension, with values in the range 210 to 230 dynes $/ \mathrm{cm}$, the barium crowns high, with values around 260 to 310 dynes $/ \mathrm{cm}$, and the other glasses intermediate. 


\section{References}

[1] F. C. Champion and N. Davy, Properties of matter, p. 126 (Prentice-Hall, Inc., New York, N. Y. 1937).

[2] A. A. Appen, Optiko-Mechan. Prom. 6, No. 3, F-12; No. 12, 17f (1936).

[3] W. N. Harrison and D. G. Moore, Surface tensions of vitreous enamel frits at and near firing temperatures, J. Research NBS 21, 337 (1938) RP1133.

[4] C. L. Babcock, Surface tension by a modified eylinder method, J. Am. Ceram. Soc. 23, 13 (1940).

[5] A. E. Badger, C. W. Parmelee, and A. E. Williams, Surface tension of various molten glasses, J. Am. Ceram. Soc. 20, 325 (1937).
[6] C. A. Bradley, Jr., Measurement of surface tension of viscous liquids, J. Am. Ceram. Soc. 21, 339 (1938).

[7] H. Freundlich, Colloid and capillary chemistry (E. P. Dutton \& Co., Ine., New York, N. Y., 1922).

[8] W. H. Parsons and H. Insley, Attack on refractory clay pots by optical glass, J. Research NBS 36, 31 (1946) RP1689.

[9] E. E. Day, Statistical analysis, p. 208 (The Macmillan Co., 60 Fifth Ave., New York, N. Y., 1937).

Washington, October 10, 1946. 